Correction

\title{
Correction: Paszkiewicz et al. A Peripheral CB1R Antagonist Increases Lipolysis, Oxygen Consumption Rate, and Markers of Beiging in 3T3-L1 Adipocytes Similar to RIM, Suggesting That Central Effects Can Be Avoided. Int. J. Mol. Sci. 2020, 21, 6639
}

\author{
Rebecca L. Paszkiewicz ${ }^{1}$, Richard N. Bergman ${ }^{1}$, Roberta S. Santos ${ }^{1}{ }^{\mathbb{D}}$, Aaron P. Frank ${ }^{1}$, Orison O. Woolcott ${ }^{1}$, \\ Malini S. Iyer ${ }^{1}$, Darko Stefanovski ${ }^{2}$, Deborah J. Clegg ${ }^{3}$ and Morvarid Kabir ${ }^{1, * \mathbb{D}}$
}

check for

updates

Citation: Paszkiewicz, R.L.; Bergman, R.N.; Santos, R.S.; Frank, A.P.; Woolcott, O.O.; Iyer, M.S.; Stefanovski, D.; Clegg, D.J.; Kabir, M. Correction: Paszkiewicz et al. A Peripheral CB1R Antagonist Increases Lipolysis, Oxygen Consumption Rate, and Markers of Beiging in 3T3-L1 Adipocytes Similar to RIM, Suggesting That Central Effects Can Be Avoided. Int. J. Mol. Sci. 2020, 21, 6639. Int. J Mol. Sci. 2021, 22, 4366. https:// doi.org/10.3390/ijms22094366

Received: 24 March 2021 Accepted: 26 March 2021 Published: 22 April 2021

Publisher's Note: MDPI stays neutra with regard to jurisdictional claims in published maps and institutional affiliations.

Copyright: (c) 2021 by the authors. Licensee MDPI, Basel, Switzerland. This article is an open access article distributed under the terms and conditions of the Creative Commons Attribution (CC BY) license (https:// creativecommons.org/licenses/by/ $4.0 /)$.
1 Sports Spectacular Diabetes and Obesity Wellness and Research Center, Cedars-Sinai Medical Center, Los Angeles, CA 90048, USA; RPaszkiewicz@mednet.ucla.edu (R.L.P.); Richard.Bergman@cshs.org (R.N.B.); santosrds1@gmail.com (R.S.S.); aaronpfrank@gmail.com (A.P.F.); Orison.Woolcott@gmail.com (O.O.W.); malini.s.iyer@gmail.com (M.S.I.)

2 School of Veterinary Medicine, University of Pennsylvania, Philadelphia, PA 19104, USA; sdarko@vet.upenn.edu

3 The College of Nursing and Health Professions, Drexel University, Philadelphia, PA 19104, USA; djc387@drexel.edu

* Correspondence: morvarid.kabir@cshs.org; Tel.: +1-310-967-2790

The authors wish to make the following corrections to this paper [1]: On page 6, the curve in Figure 5a was switched with Figure 7c on Page 7. Thus, Figure 5 should be replaced with the following figure (Figure 1), and Figure 7 with the following figure (Figure 2).
(A)

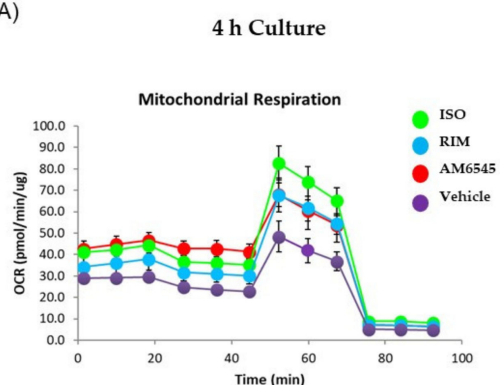

(C)

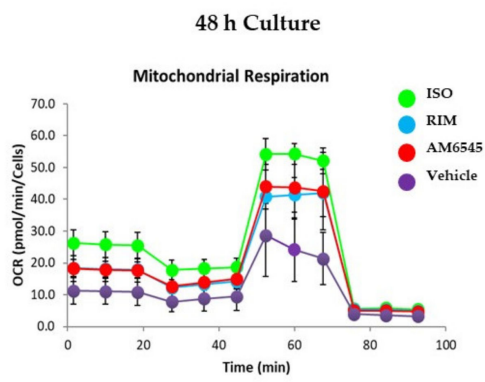

(B)

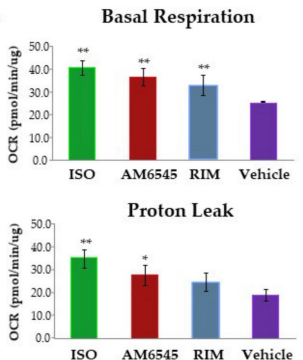

(D)

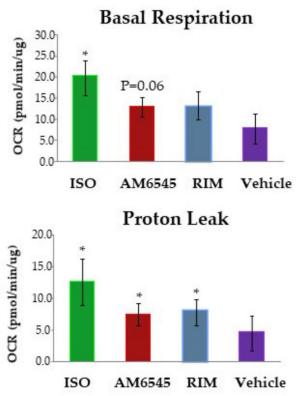

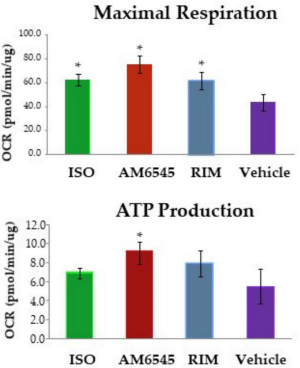

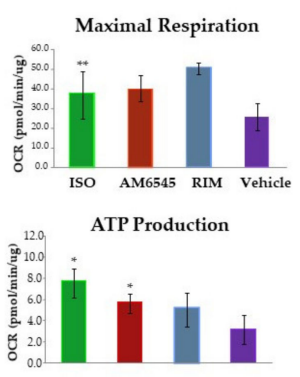

ISO AM6545 RIM Vehicle
Figure 1. Peripheral cannabinoid receptor 1 (CB1R) antagonist increased oxygen consumption rate (OCR). 3T3-L1 adipocytes were treated with AM6545, rimonabant (RIM), and isoproterenol (ISO) at 4 and $48 \mathrm{~h}$. OCR was measured in basal conditions or in response to sequential treatment with 
2 oligomycin, 0.75 FFCP (respiratory chain uncoupler), and $1 \mu \mathrm{M}$ rotenone/antimycin A (inhibitor of respiratory chain complex I and complex III) using the Seahorse XF-24 analyzer. (A) Mitochondrial respiration curves at $4 \mathrm{~h}$ after treatment. (B) Parameters calculated from the tracing at $4 \mathrm{~h}$ after treatment. (C) Mitochondrial respiration curves $48 \mathrm{~h}$ after treatment. (D) Parameters calculated from the OCR at $48 \mathrm{~h}$ after treatment. Data on graphs are presented as the mean \pm standard error of mean (SEM) of 4 independent rounds of the cells; ${ }^{*} p<0.05$ vs. control, ${ }^{* *} p<0.01$ vs. control.

(A)

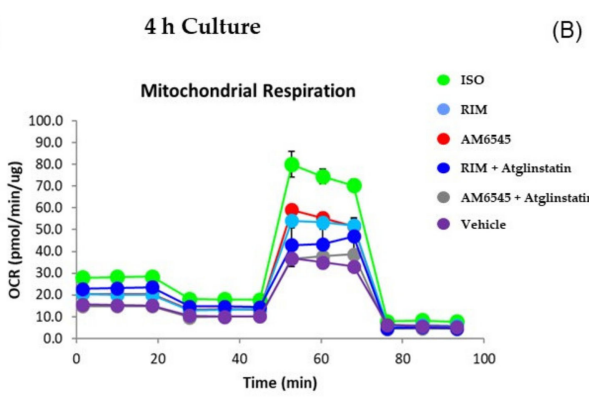

(C)

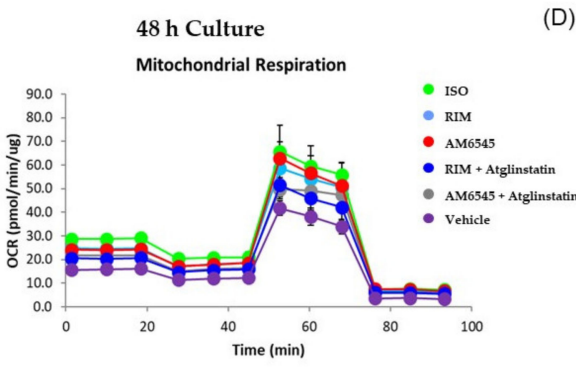

(B)

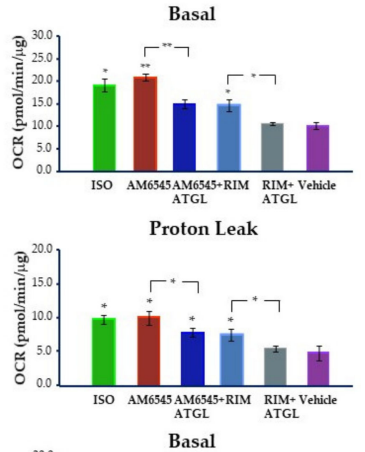

(D)

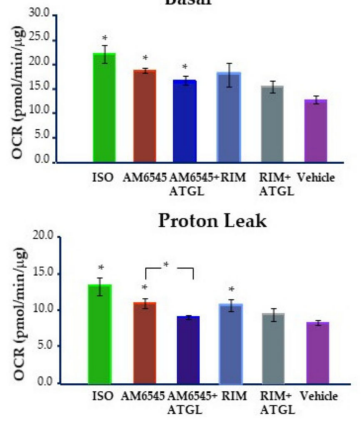

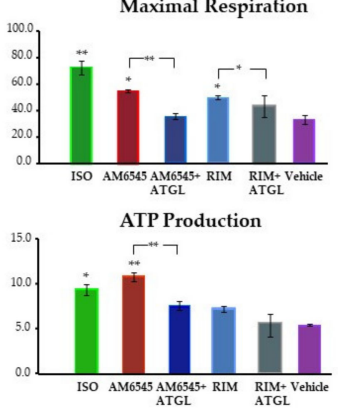

Maximal Respiration

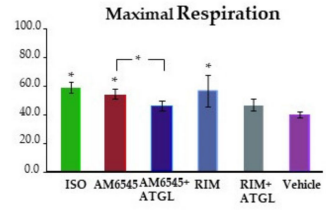

ATP Production

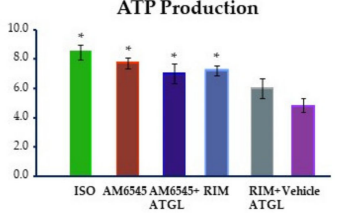

Figure 2. Peripheral cannabinoid receptor 1 (CB1R) antagonist increased oxygen consumption rate (OCR) inhibited by lipolysis blocker. 3T3-L1 adipocytes were treated with AM6545 and rimonabant (RIM) with and without Atglinstatin, and isoproterenol (ISO) at 4 and $48 \mathrm{~h}$. OCR was measured in basal conditions or in response to sequential treatment with $2 \mu \mathrm{M}$ oligomycin, $0.75 \mu \mathrm{M}$ FFCP (respiratory chain uncoupler), and $1 \mu \mathrm{M}$ rotenone/antimycin A (inhibitor of respiratory chain complex I and complex III) using the Seahorse XF-24 analyzer. (A) Mitochondrial respiration tracing using Seahorse at $4 \mathrm{~h}$ after treatment. (B) Parameters calculated from the tracing at $4 \mathrm{~h}$ after treatment. (C) Mitochondrial respiration tracing $48 \mathrm{~h}$ after treatment. (D) Parameters calculated from the tracing at $48 \mathrm{~h}$ after treatment. Data on graphs are presented as the mean \pm standard deviation (SD) of 4 independent rounds of the cells; ${ }^{*} p<0.05$ vs. control, ${ }^{* *} p<0.01$ vs. control.

The authors apologize for any inconvenience caused and state that the scientific conclusions are unaffected. The original article has been updated.

Conflicts of Interest: The authors declare no conflict of interest.

\section{Reference}

1. Paszkiewicz, R.L.; Bergman, R.N.; Santos, R.S.; Frank, A.P.; Woolcott, O.O.; Iyer, M.S.; Stefanovski, D.; Clegg, D.J.; Kabir, M. A Peripheral CB1R Antagonist Increases Lipolysis, Oxygen Consumption Rate, and Markers of Beiging in 3T3-L1 Adipocytes Similar to RIM, Suggesting that Central Effects Can Be Avoided. Int. J. Mol. Sci. 2020, 21, 6639. [CrossRef] [PubMed] 